\title{
BMJ Open Development and validation of a socioculturally competent trust in physician scale for a developing country setting
}

\author{
Vijayaprasad Gopichandran, ${ }^{1}$ Edwin Wouters, ${ }^{2,3}$ Satish Kumar Chetlapalli ${ }^{1}$
}

To cite: Gopichandran V, Wouters E, Chetlapalli SK. Development and validation of a socioculturally competent trust in physician scale for a developing country setting. BMJ Open 2015;5:e007305.

doi:10.1136/bmjopen-2014007305

- Prepublication history for this paper is available online. To view these files please visit the journal online (http://dx.doi.org/10.1136/ bmjopen-2014-007305).

Received 26 November 2014 Revised 6 April 2015 Accepted 12 April 2015

CrossMark

${ }^{1}$ School of Public Health, SRM University, Kancheepuram, India ${ }^{2}$ Centre for Longitudinal \& Life Course Studies, University of Antwerp, Antwerp, Belgium ${ }^{3}$ Centre for Health Systems Research \& Development, University of the Free State, Bloemfontein, South Africa

\section{Correspondence to}

Dr Vijayaprasad

Gopichandran;

vijay.gopichandran@gmail. com

\section{ABSTRACT}

Trust in physicians is the unwritten covenant between the patient and the physician that the physician will do what is in the best interest of the patient. This forms the undercurrent of all healthcare relationships. Several scales exist for assessment of trust in physicians in developed healthcare settings, but to our knowledge none of these have been developed in a developing country context.

Objectives: To develop and validate a new trust in physician scale for a developing country setting. Methods: Dimensions of trust in physicians, which were identified in a previous qualitative study in the same setting, were used to develop a scale. This scale was administered among 616 adults selected from urban and rural areas of Tamil Nadu, south India, using a multistage sampling cross sectional survey method. The individual items were analysed using a classical test approach as well as item response theory. Cronbach's $\alpha$ was calculated and the item to total correlation of each item was assessed. After testing for unidimensionality and absence of local dependence, a 2 parameter logistic Semajima's graded response model was fit and item characteristics assessed.

Results: Competence, assurance of treatment, respect for the physician and loyalty to the physician were important dimensions of trust. A total of 31 items were developed using these dimensions. Of these, 22 were selected for final analysis. The Cronbach's $\alpha$ was 0.928 . The item to total correlations were acceptable for all the 22 items. The item response analysis revealed good item characteristic curves and item information for all the items. Based on the item parameters and item information, a final 12 item scale was developed. The scale performs optimally in the low to moderate trust range.

Conclusions: The final 12 item trust in physician scale has a good construct validity and internal consistency.

\section{INTRODUCTION}

Healthcare is a dynamic social institution, and trust forms an integral part of human interactions with the healthcare system. Trust

\section{Strengths and limitations of this study}

- This is the first study, to the best of our knowledge, to have developed and validated a scale to assess trust in physicians in a developing country context.

- The scale to assess trust has organically developed from qualitative assessment of trust in the same region in India.

- This study has utilised the strengths of a classical test as well as item response analyses for scale development and validation.

- This study has performed only construct, content validity and internal consistency. There is a need to further validate this scale for predictive validity.

in healthcare is all the more important given the state of vulnerability inherent in illness. Patient trust in the physician has been defined as a collection of expectations that patients have from their doctor. ${ }^{1}$ Certain other researchers have defined patient trust as a feeling of reassurance or confidence in the doctor. ${ }^{2}$ Another interesting definition of trust, which is apt for the healthcare setting, is "an unwritten agreement between two or more parties for each party to perform a set of agreed upon activities without fear of change from any party." 3

Trust in physicians is of inherent value in healthcare. Ample research has demonstrated the positive association between trust and individual health outcomes; it is implicit and integral to healthcare relationships. ${ }^{4}$ Several studies have indicated that greater trust is associated with greater adherence to treatment and better self management of chronic illnesses such as diabetes. ${ }^{5-8}$ Patients who have greater trust in physicians show better follow-up and continuity of care. ${ }^{9}$ Strong patient-physician relationships of trust have been shown to be associated with 
greater self efficacy of patients. ${ }^{10}$ Trust in physicians is also associated with open disclosure even of sensitive information, which helps in care. ${ }^{5}$ A patient's self-rated health status is also better when there is better trust. ${ }^{11}$ However, it has to be mentioned that while trust is associated with several of these outcomes, a strong causal inference cannot be made.

However, trust is a difficult construct to measure. To the best of our knowledge, scales that have been developed to measure trust have emerged from the developed world. Six tools to measure trust in the healthcare setting have been described in a review by Goudge and Gilson. These are, Trust in Primary Care Physician Scale by Hall $e t a l,{ }^{12}$ Trust in Physician Scale by Anderson and Dedrick, ${ }^{1}$ Physician Trust Scale by Kao et al (1998), Medical Professions Trust Scale by Hall et al, ${ }^{12}$ Health Insurance Organization Trust Scale by Zheng $e t a l^{13}$ and Whole Health System Trust Scale by Straten et al. ${ }^{14}$ Out of these six tools, five have been developed in the USA, and one tool by Straten et al in the Netherlands. They measure different aspects of trust. Three of these tools have been developed in Wake Forest University, North Carolina. ${ }^{15}$ Egede and Ellis developed a Multidimensional Trust in Health Care System Scale that simultaneously measures trust in physician, trust in institutions and trust in insurer or payer. This 17 item scale has good psychometric properties and also correlated well with patient centred care, patient satisfaction, adherence to medication and social support. ${ }^{16}$ Dugan, Trachtenberg and Hall developed an abridged trust scale that simultaneously measures trust in physician, health insurer and the medical profession. It has five items in each subscale. The scale has good psychometric properties. ${ }^{17}$ Goold et al ${ }^{18}$ developed a scale to measure trust in the health insurer. This tool is a patient centred measure of trust in insurers. Administrative competence, clinical competence, advocacy, beneficence, fairness, honesty and openness, are some of the domains covered in this trust scale. A unique scale was developed to measure distrust in healthcare. This scale has 10 items: 4 measuring honesty, 2 measuring confidentiality, and the other 2 domains being fidelity and competence. This scale also has good psychometric properties. ${ }^{19}$ The Primary Care Assessment Survey (PCAS) by Safran et al is another tool covering seven important domains of healthcare. One of the domains covered is trust. It has a very high reliability of all the seven domains. ${ }^{6}$ Leisen and Hyman developed Patient Trust in their Physician Scale in 2001. It comprises of two overarching dimensions of trust, namely, technical competence and benevolence. Evaluating problems, providing appropriate and effective treatment, predisposing factors and structural/staffing factors, are components of the competence domain, and understanding the patient's individual experiences, expressing caring, communicating clearly and completely, building partnership, demonstrating honesty and keeping information confidential, are components of the benevolence domain. ${ }^{20}$
The dimensions and determinants of trust in healthcare in developing countries are likely to be very different. In many developing healthcare settings there is deprivation of resources, lack of universal health access, low public expenditure on healthcare, high out of pocket expenditure on health and poorly regulated private practice. ${ }^{21}$ Economic factors, uncertainties in access to health, emotional factors and implicit acceptance of paternalism in clinical care are all likely to impact the social interactions in the healthcare setting, thus leading to different dimensions. A qualitative exploration of trust in healthcare undertaken from India showed that the important dimensions of trust are perceived competence, assurance of treatment, loyalty and respect. ${ }^{22}$ Of these, only competence is a dimension that has been identified before. The other three are culturally unique to developing country settings. A cross sectional community-based survey was carried out to validate the Trust in Physicians scale developed by Anderson and Diedrick ${ }^{1}$ in this local setting. The questionnaire was translated to Tamil and back translated to English to ensure validity of translation. The findings of this survey are presented elsewhere. ${ }^{23}$ The exploratory factor analysis showed that the scale was unidimensional, and did not separate into the original three dimensional factor structure of the trust in physician questionnaire described by Anderson and Dedrick. Further, it was noticed that some of the components of the Anderson and Dedrick scale, such as doubts about the doctor's competence and confidentiality, were not relevant to the local context where the questionnaire was administered. This study underscored the importance of a new scale for trust in physicians in this context.

Therefore, there is a need to assess trust in healthcare in these settings, with a culturally and socially appropriate scale developed and validated in the context. This study was carried out to develop and validate a trust in physician scale relevant to the developing country context in India.

\section{METHODS}

\section{Study setting}

All parts of the study were carried out in Tamil Nadu, a state in south India. India has a large public health system; the system runs through a decentralised state budget allocation. With the advent of the National Rural Health Mission, a flagship health system strengthening programme of the government of India, started in 2005 , the public health system received a fillip in terms of decentralisation, better platforms for community engagement with healthcare, better accountability mechanisms and greater fund allocation. ${ }^{24}$ Alongside this strong public health system there is also a powerful private sector in healthcare. Private health providers, who deliver healthcare services for a fee, are the highest contributors to health services in India. There is a growing corporate healthcare industry in the metropolitan cities that 
provides international quality health services to the people in the country and also serves as hubs for health tourism. In addition to the private and public health systems, there is a large network of unorganised, unqualified medical practitioners providing all levels of healthcare. ${ }^{25}$ The overall health expenditure is about $4 \%$ of the gross domestic product (GDP) and the government budget allocation for healthcare is less than $1 \%$ of the GDP $^{26}$ The remaining health expenditure is largely out of pocket. This leads to significant impoverishment, and catastrophic health expenditure is one of the commonest reasons for indebtedness in the country. ${ }^{27}$ Tamil Nadu is one of the high performing states in India with respect to health indicators. It has one of the well-functioning models of healthcare in the country but still several pockets, especially poor rural areas and migrant urban populations, remain largely underserved. ${ }^{28}$ The inefficient public health system, burgeoning private healthcare, rising cost of healthcare, and irrational and unregulated practices, make the study setting very different and unique from the other countries from where studies of trust in healthcare have previously emerged. Henceforth, we will refer to these health settings as developing health systems.

\section{Qualitative study to identify dimensions of trust in physicians}

The qualitative study to explore the dimensions of trust in physicians has been described in detail elsewhere. ${ }^{22}$ In-depth interviews were conducted among vulnerable groups of people in various parts of the state of Tamil Nadu. A grounded theory approach was used to identify the emerging themes from these interviews. The main dimensions of trust that were identified were: perceived competence of the physician, assurance of treatment, confidence in the physician, respect given to the physician and loyalty to the physician. While the first three were formative dimensions of trust, the latter two were reflective.

\section{Development of items for the scale}

Statements were generated to represent each of the dimensions of trust identified in the qualitative study. To capture the domain of perceived competence of the physicians' statements such as appropriateness of medicines given, laboratory tests performed, quick relief, recommendations by friends and relatives, and lack of adverse effects of medicines, were included. Treatment assurance was represented in statements pertaining to assurance of treatment, irrespective of the time of day, ability to pay or the type of illness experienced. The statement "I feel that all of my illness will become all right when I go to this doctor" represented confidence. There were items representing loyalty, which included, going to the doctor for any illness, taking other treatments only after getting approval from the doctor, and referring all family and friends to only this doctor. There were also unique items that represented respect for the physician. The questionnaire items were circulated to 10 people: 3 physicians, 2 public health professionals and 5 lay persons, to get their opinion on the face validity of the questionnaire. These individuals were asked to rate each question on a scale of 1 to 5 on the extent to which they represent the dimensions of trust in physicians with score 1 being least representative and 5 being most representative. The items that scored least were removed from the final scale. The questionnaire was developed in English and translated to the local language, Tamil, by the researcher. An uninvolved person back translated the Tamil version of the questionnaire to English. This back translated version was checked for validity of the translation. Appropriate changes to the translation were made to ensure validity of the translation. There were a total of 31 items reflecting the five dimensions of trust in physicians.

\section{Sampling}

The sample size of 600 was calculated according to the heuristics for sampling in multivariate modelling, which requires that there should be at least 20 observations per variable of analysis. ${ }^{29}$ Four districts were first selected by a simple random sampling method from the 32 districts of Tamil Nadu. Two of these districts are predominantly urban and two are predominantly rural. Three urban wards and eight rural blocks were selected from each district by a probability proportion to size method. From each selected block/ward, 50 adult men and women were interviewed if they reported having a regular primary care physician/facility to whom/where they went for their common minor illnesses.

\section{Measurement}

The study was conducted between June and October 2012. The selected participants were requested to answer the questions based on the primary care physician whom they consulted for their minor ailments. For example, the interviewer would state "I get the confidence that all my illness will get alright when I go to the doctor" (domain-perceived competence), "The doctor gives appropriate medications for my diseases" (domain -perceived competence) reflecting attributes of trust. The respondents rated the statements on a five point Likert scale between "Strongly agree" to "Strongly disagree". To reduce selection bias, the sample was selected using a multistage technique. Hospital based sampling was avoided. The researcher administered the questionnaires along with two other trained investigators. Though the researcher is a physician by profession, this was not made explicit to the respondents during the interviews, in order to avoid reporting bias. Though the responses could have influenced the attitudes of the researcher, this is unlikely to have influenced the study, as the questionnaire administration process was standardised and there was very little scope for interpretation or reactions at the time of the interview. However, it is likely that the non-verbal communication signals 
Table 1 Characteristics of the study participants

\begin{tabular}{|c|c|c|c|}
\hline Characteristic & Categories & $\begin{array}{l}\text { Frequency } \\
\text { (percentage) }\end{array}$ & $\begin{array}{l}\text { Population characteristics } \\
\text { of Tamil Nadu state }\end{array}$ \\
\hline \multirow[t]{6}{*}{$\overline{\text { Age }}$} & $18-25$ & $158(25.3)$ & 19 \\
\hline & $26-35$ & 204 (32.6) & 16.7 \\
\hline & $36-45$ & $104(16.6)$ & 14 \\
\hline & $46-55$ & $85(13.6)$ & 10 \\
\hline & $56-65$ & $45(7.2)$ & 7 \\
\hline & $>65$ & $29(4.6)$ & 5 \\
\hline \multirow[t]{2}{*}{ Sex } & Male & $252(40.9)$ & 50.2 \\
\hline & Female & $364(59.1)$ & 49.8 \\
\hline \multirow{2}{*}{ Place of residence } & Urban & $124(20.1)$ & 48.45 \\
\hline & Rural & 501 (79.9) & 51.55 \\
\hline \multirow[t]{4}{*}{ Education } & No formal education & $89(14.4)$ & Literate-73.8 \\
\hline & Schooling & $270(43.8)$ & Illiterate-26.2 \\
\hline & Graduation & 135 (21.9) & \\
\hline & $P G$ and professional & $122(19.8)$ & \\
\hline \multirow[t]{8}{*}{ Occupation } & Service sector & $165(26.8)$ & 22 \\
\hline & Home maker & $159(25.9)$ & * \\
\hline & Labourer & $92(15)$ & 26 \\
\hline & Unemployed & $72(11.7)$ & * \\
\hline & Professional & $42(6.8)$ & 8 \\
\hline & Agricultural land Owner & $38(6.2)$ & 40 \\
\hline & Business & 30 (4.9) & 8 \\
\hline & Skilled workers & $17(2.8)$ & * \\
\hline Any sickness in the & Yes & $323(52.5)$ & \\
\hline Past 3 months & No & $292(47.5)$ & \\
\hline
\end{tabular}

between the physician-researcher and the participants could have altered the responses. This needs to be kept in mind while interpreting the results of the study. By using a standardised questionnaire and standardisation of the questionnaire administration process, the chance of interviewer bias was controlled.

\section{Psychometric analysis}

There are two distinct theoretical frameworks for development and validation of psychometric instruments, namely, classical test theory and item response theory. In classical test theory, the analysis focuses on the total test score. The validation and scaling of a tool using classical test theory is highly sample dependent. The properties of difficulty or discrimination of the individual items are not constant across samples. Another major disadvantage of the classical test theory is that the total scores and thus the estimate of the true ability are also related to the choice of questions in the test. Therefore, the ability levels may not be comparable across different scales. The greatest advantage of using classical test theory is that the assumptions for the theoretical models are very lenient and easy to meet. In contrast, the Item response theory is based on strong assumptions that are difficult to meet. Therefore, fitting an item response model is a challenge in itself. But the IRT model is very useful because it looks at the probability of getting an expected response to a question at various levels of the ability under study. The parameters that are estimated are sample invariant and, also, the ability that is estimated is a close measure of the true ability, independent of the questions used. $^{30}$ This study has used the strengths of the classical test theory and item response theory. The data were managed using SPSS Statistics V.17.0.1, IBM SPSS Amos V.20 and Item Response Theory for Patient Reported Outcomes (IRTPRO) V.2.1. ${ }^{31-33}$ All the 31 items in the questionnaire relating to the dimensions of trust in the physician were assessed in this analysis. Classical test analysis of the items was carried out by performing an internal consistency test using Cronbach's $\alpha$, item-to-total correlation and interitem correlations. Confirmatory factor analysis (CFA) was carried out to assess dimensionality of the 22 selected items from the total of 31. Standardised root mean squared residuals (SRMR) of less than 0.08, comparative fit index (CFI) greater than 0.95, Tucker Lewis index (TLI) greater than 0.95 and root mean square error approximation (RMSEA) less than 0.06, were used for assessing fitness of the CFA model. ${ }^{34}$ Local dependence was checked by performing the bifactor LD-X ${ }^{2}$ values considering a value of greater than 10 to indicate local dependence. ${ }^{35}$ After confirming unidimensionality and local independence, Samejima's Graded Response Model was fit for the selected 22 questions. ${ }^{36}$ Two types of models were fit, one parameter logistic (1PL) and two PL (2PL). The Akaike information criterion (AIC) and Bayesian information criterion (BIC), and -2log likelihood, were computed for the two models. ${ }^{37}$ The model 
Table 2 Classical test properties of the selected 22 items of the new trust in physician scale

\begin{tabular}{|c|c|c|}
\hline Item & $\begin{array}{l}\text { Item to total } \\
\text { correlation }\end{array}$ & $\begin{array}{l}\text { Cronbach's } \alpha \\
\text { if item deleted }\end{array}$ \\
\hline The doctor does appropriate blood tests and other tests to diagnose my disease & 0.532 & 0.924 \\
\hline The doctor gives appropriate medications for my disease & 0.619 & 0.923 \\
\hline The doctor prescribes appropriate number of medicines based on the nature of the illness & 0.636 & 0.922 \\
\hline The doctor prescribes more expensive medicines for serious illnesses & 0.406 & 0.927 \\
\hline The doctor's treatment relieves the illness quickly & 0.684 & 0.922 \\
\hline The illness gets relieved with just one visit, there is no need for repeat visits & 0.617 & 0.923 \\
\hline There are no side effects to the medicines prescribed by the doctor & 0.589 & 0.923 \\
\hline Friends, relatives and neighbours speak well about the treatment provided by the doctor & 0.581 & 0.923 \\
\hline Friends, relatives and neighbours recommend me to go to the doctor & 0.613 & 0.923 \\
\hline I get the confidence that all my illness will get alright when I go to the doctor & 0.660 & 0.922 \\
\hline There is a big crowd in the clinic of the doctor & 0.469 & 0.925 \\
\hline If I go to the doctor, I will surely get good treatment for my illness & 0.675 & 0.922 \\
\hline The doctor gives me good treatment irrespective of whether or not I have money to pay & 0.455 & 0.926 \\
\hline The main intention of the doctor is to treat my illness and not anything else & 0.637 & 0.922 \\
\hline $\begin{array}{l}\text { Irrespective of what time of the day it is, whenever I go, I can get good treatment from the } \\
\text { doctor }\end{array}$ & 0.491 & 0.925 \\
\hline Whatever illness I have, I will go only to this doctor & 0.591 & 0.923 \\
\hline Even if I go to another doctor, I will take the treatment only if this doctor approves it & 0.457 & 0.927 \\
\hline I will bring my family members only to this doctor & 0.620 & 0.923 \\
\hline I will recommend only this doctor to all those who ask me & 0.695 & 0.921 \\
\hline I respect the doctor a lot & 0.720 & 0.921 \\
\hline I think the doctor is a very learned person & 0.662 & 0.922 \\
\hline I admire the doctor & 0.605 & 0.923 \\
\hline
\end{tabular}

that showed lower values for the AIC, BIC and $-2 \log$ likelihood, was the appropriate one. Based on the model, the item parameters were calculated. The item characteristic curves and item information functions were plotted. The level of overlap of the graded responses in the Likert scale, the extent of

Table 3 Confirmatory factor analysis of the 22 items confirming a unidimensional structure

\begin{tabular}{|c|c|c|c|}
\hline Explanatory variable & $\begin{array}{l}\text { Regression } \\
\text { weight }\end{array}$ & SE & p Value \\
\hline The doctor does appropriate blood tests and other tests to diagnose my disease & 0.565 & 0.01 & $<0.001$ \\
\hline The doctor gives appropriate medications for my disease & 0.653 & 0.078 & $<0.001$ \\
\hline The doctor prescribes appropriate number of medicines based on the nature of the illness & 0.672 & 0.083 & $<0.001$ \\
\hline The doctor prescribed more expensive medicines for serious illnesses & 0.431 & 0.088 & $<0.001$ \\
\hline The doctor's treatment relieves the illness quickly & 0.732 & 0.081 & $<0.001$ \\
\hline The illness gets relieved with just one visit, there is no need for repeat visits & 0.652 & 0.089 & $<0.001$ \\
\hline There are no side effects to the medicines prescribed by the doctor & 0.613 & 0.092 & $<0.001$ \\
\hline Friends, relatives and neighbours speak well about the treatment provided by the doctor & 0.592 & 0.085 & $<0.001$ \\
\hline Friends, relatives and neighbours recommend me to go to the doctor & 0.639 & 0.087 & $<0.001$ \\
\hline I get the confidence that all my illness will get alright when I go to the doctor & 0.687 & 0.084 & $<0.001$ \\
\hline There is a big crowd in the clinic of the doctor & 0.493 & 0.075 & $<0.001$ \\
\hline If I go to the doctor, I will surely get good treatment for my illness & 0.731 & 0.081 & $<0.001$ \\
\hline The doctor gives me good treatment irrespective of whether or not I have money to pay & 0.436 & 0.096 & $<0.001$ \\
\hline The main intention of the doctor is to treat my illness and not anything else & 0.644 & 0.09 & $<0.001$ \\
\hline $\begin{array}{l}\text { Irrespective of what time of the day it is, whenever I go, I can get good treatment from the } \\
\text { doctor }\end{array}$ & 0.565 & 0.1 & $<0.001$ \\
\hline Whatever illness I have, I will go only to this doctor & 0.581 & 0.104 & $<0.001$ \\
\hline Even if I go to another doctor, I will take the treatment only if this doctor approves it & 0.427 & 0.105 & $<0.001$ \\
\hline I will bring my family members only to this doctor & 0.613 & 0.095 & $<0.001$ \\
\hline I will recommend only this doctor to all those who ask me & 0.702 & 0.098 & $<0.001$ \\
\hline I respect the doctor a lot & 0.762 & 0.084 & $<0.001$ \\
\hline I think the doctor is a very learned person & 0.700 & 0.088 & $<0.001$ \\
\hline I admire the doctor & 0.603 & 0.102 & $<0.001$ \\
\hline
\end{tabular}




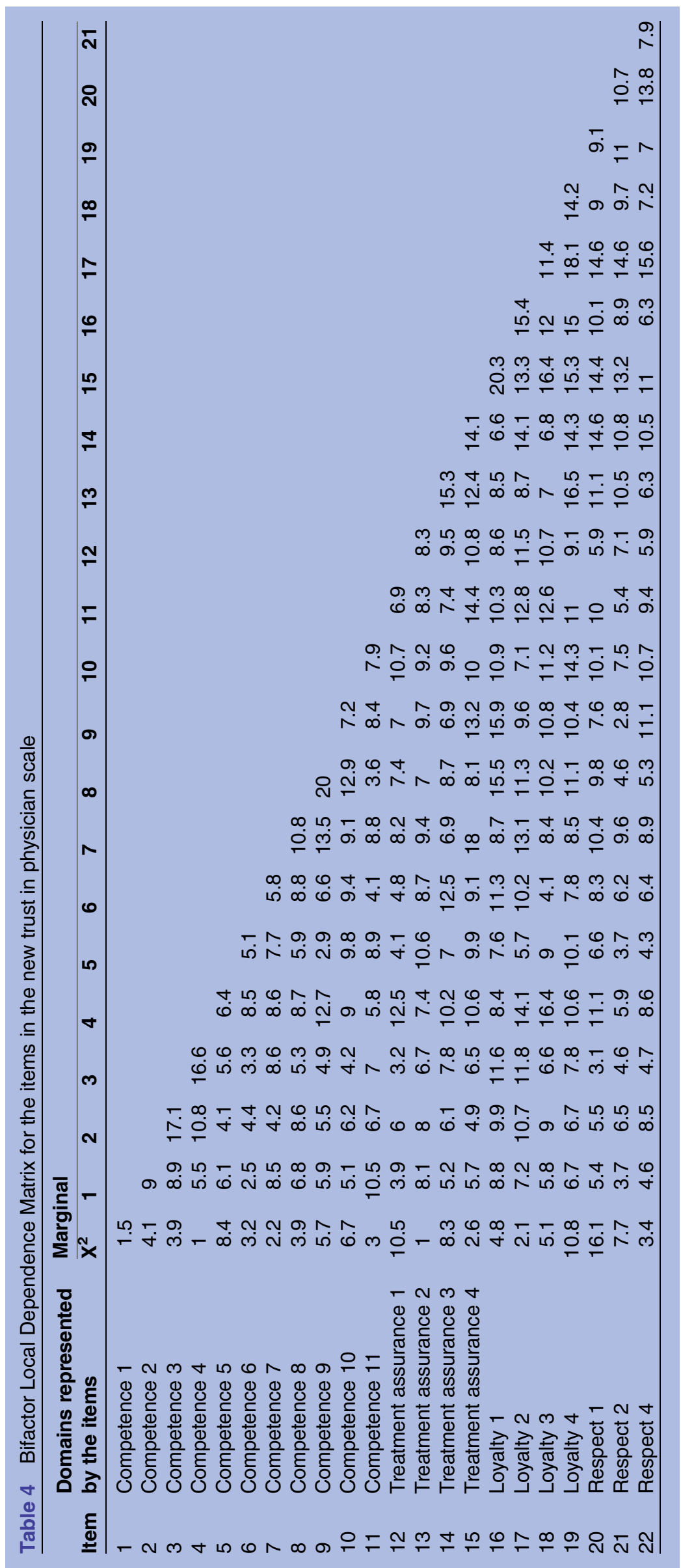


Table 5 The model fit parameters of the $1 \mathrm{PL}$ and $2 \mathrm{PL}$ models in item response analysis

\begin{tabular}{llll}
\hline Model type & AIC & BIC & -2 log likelihood \\
\hline $1 \mathrm{PL}$ & 27578.96 & 27972.63 & -13700.48 \\
$2 \mathrm{PL}$ & 27327.17 & 27813.72 & -13553.58 \\
\hline
\end{tabular}

$\mathrm{AIC}$, Akaike information criterion; BIC, Bayesian information criterion; PL, parameter logistic.

discrimination of each response and the item information values were used to select the appropriate questionnaire items. Test information function was also assessed.

\section{Ethical considerations}

The Institutional Ethics Group assessed the study protocol and identified minimal ethical risks. They submitted the protocol to the Institutional Review Board and Ethics Committee of the School of Public Health, SRM University, registered under the Office for Human Research Protections (OHRP) of the USA Department of Health and Human Services (USHHS). The committee reviewed the study protocol and approved the study. Since the ethical risks were minimal and since obtaining a written informed consent may deter participants from openly discussing some sensitive issues related to the physician-patient relationship, the committee approved that a verbal informed consent be obtained from all participants in the qualitative and in the quantitative components of the study.

\section{RESULTS}

Out of a total of 625 survey responses, 9 were incomplete and hence were removed from analysis. The characteristics of the remaining 616 respondents are shown in table 1 . The characteristics of the sample are compared with population characteristics of Tamil Nadu. ${ }^{38-40}$ It can be seen that compared to the Tamil Nadu population, the sample had a greater representation of women, younger aged people and people with greater educational attainment.

Of the 31 items that were included in the questionnaire, only 22 items had good item to total correlation (>0.4) good inter-item correlation $(0.4-0.7) .{ }^{41}$ So these 22 items were further analysed. The Cronbach's $\alpha$ of the 22 item scale was 0.928 . The items, their item to total correlations and Cronbach's $\alpha$ if respective items are removed from the scale, are shown in table 2.

A CFA model was constructed with a single latent variable, 'trust in doctors', and all the 22 questions as explanatory variables. The model fit indices revealed SRMR of 0.06, CFI of 0.958, TLI of 0.951 and RMSEA of $0.045(90 \%$ CI 0.043 to 0.048$)$, thus indicating an acceptable model fit for a unidimensional construct. Table 3 shows the standardised regression weights and SEs of each of the 22 items, and their contribution to trust in doctors.

LD- $\mathrm{X}^{2}$ bifactor statistics were computed and minimal local dependence was identified between three items measuring competence, two items measuring shared community opinions about the doctor and three items

\begin{tabular}{|c|c|c|c|c|c|c|c|c|}
\hline S No & Item & A & b1 & b2 & b3 & b4 & S-X2 & p Value \\
\hline 1 & Does lab tests for diagnosis & 1.75 & -2.05 & -1.50 & -1.01 & -0.48 & 159.46 & 0.005 \\
\hline 2 & Appropriate medicines & 2.54 & -2.06 & -1.50 & -1.17 & -0.68 & 93.67 & 0.140 \\
\hline 3 & Appropriate number of medicines & 2.45 & -1.90 & -1.55 & -0.96 & -0.51 & 141.34 & 0.001 \\
\hline 4 & Expensive meds for serious illness & 1.22 & -2.17 & -1.65 & -0.76 & 0.01 & 222.19 & 0.001 \\
\hline 5 & Relieves illness quickly & 3.02 & -1.83 & -1.41 & -1.09 & -0.51 & 90.28 & 0.273 \\
\hline 6 & One visit is enough & 2.14 & -1.81 & -1.44 & -0.87 & -0.25 & 126.80 & 0.231 \\
\hline 7 & No side effects of medicines & 2.09 & -1.72 & -1.35 & -0.86 & -0.35 & 142.27 & 0.049 \\
\hline 8 & Community speaks well about doctor & 2.18 & -1.82 & -1.48 & -0.87 & -0.28 & 150.46 & 0.003 \\
\hline 9 & Community recommends the doctor & 2.46 & -1.66 & -1.38 & -0.93 & -0.32 & 122.57 & 0.047 \\
\hline 10 & Confidence & 2.55 & -1.85 & -1.48 & -0.94 & -0.29 & 120.27 & 0.081 \\
\hline 11 & Big crowd in the clinic & 1.81 & -2.28 & -1.76 & -1.05 & -0.52 & 224.29 & 0.001 \\
\hline 12 & Assured of good treatment & 3.43 & -1.80 & -1.32 & -1.00 & -0.59 & 102.69 & 0.037 \\
\hline 13 & Good treatment irrespective of pay & 1.24 & -1.85 & -1.40 & -0.71 & -0.15 & 219.84 & 0.001 \\
\hline 14 & Main intention is to treat my illness & 2.6 & -1.64 & -1.27 & -0.85 & -0.35 & 137.47 & 0.025 \\
\hline 15 & Assured of treatment at any time & 1.45 & -1.58 & -1.11 & -0.57 & 0.05 & 229.94 & 0.001 \\
\hline 16 & Whatever the illness will go only to him & 2.15 & -1.33 & -0.97 & -0.53 & -0.15 & 175.80 & 0.002 \\
\hline 17 & $\begin{array}{l}\text { Will take other doctor's prescription only } \\
\text { with permission of this doctor }\end{array}$ & 1.36 & -1.18 & -0.89 & -0.23 & 0.27 & 222.35 & 0.001 \\
\hline 18 & Will bring family members to this doctor & 2.39 & -1.46 & -1.20 & -0.69 & -0.26 & 123.10 & 0.222 \\
\hline 19 & Will recommend this doctors to others & 3.12 & -1.35 & -1.10 & -0.69 & -0.25 & 118.13 & 0.117 \\
\hline 20 & Respect & 4.00 & -1.58 & -1.30 & -0.93 & -0.49 & 72.37 & 0.466 \\
\hline 21 & Learned person & 2.97 & -1.62 & -1.35 & -0.90 & -0.40 & 125.76 & 0.011 \\
\hline 22 & Admiration & 2.14 & -1.31 & -1.09 & -0.57 & -0.06 & 141.81 & 0.095 \\
\hline
\end{tabular}




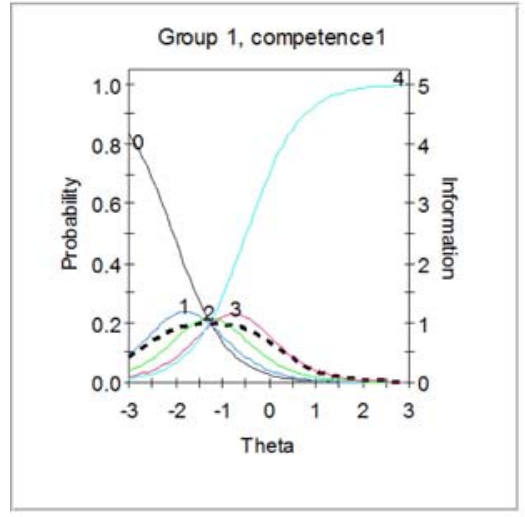

Does lab tests for diagnosis

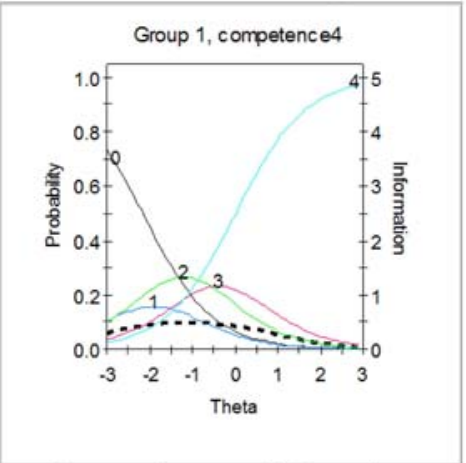

Expensive medicines for serious illness

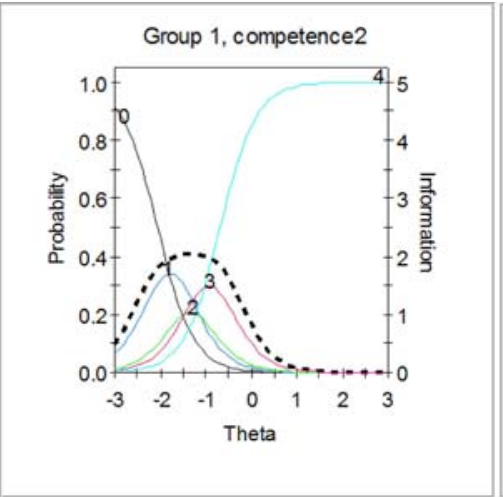

Gives appropriate medicines

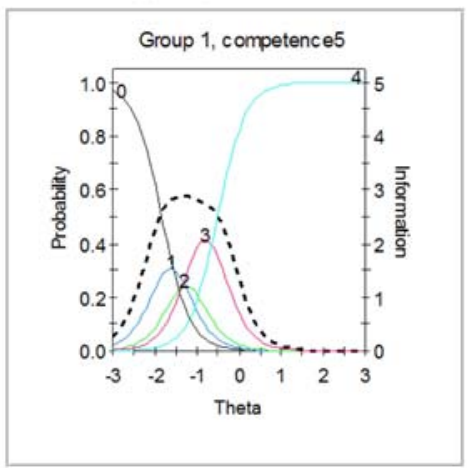

Quick relief

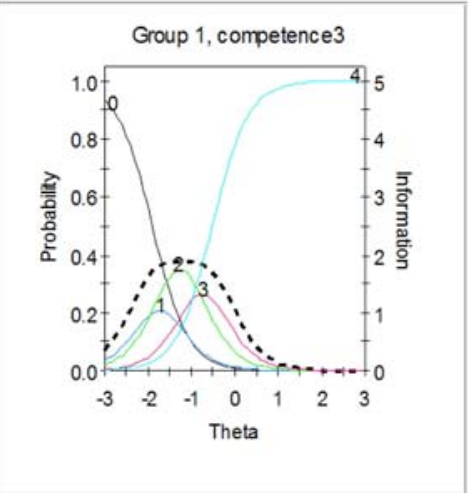

Gives appropriate number of medicines

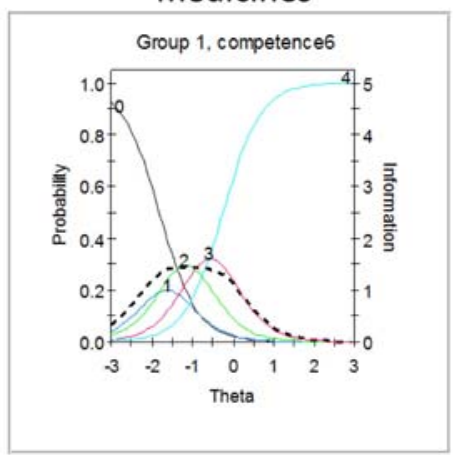

One visit is enough

Figure 1 This figure shows the Item Characteristic Curves and Item Information Functions of items in the trust in physician scale.

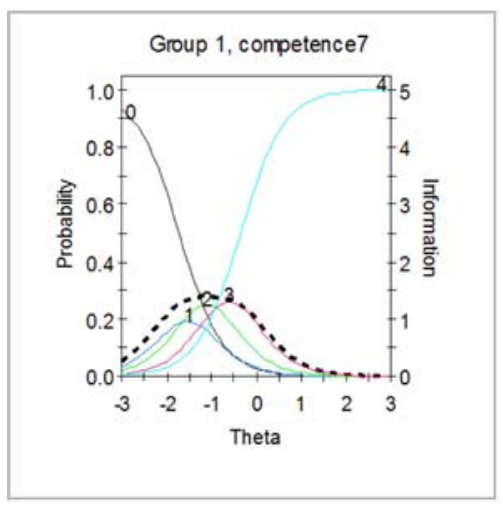

No side effects of medicines

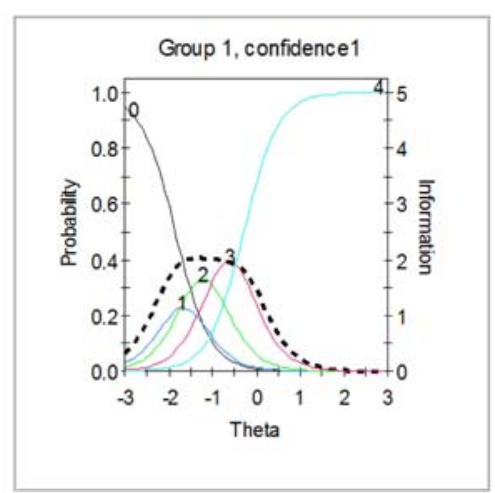

I get confidence

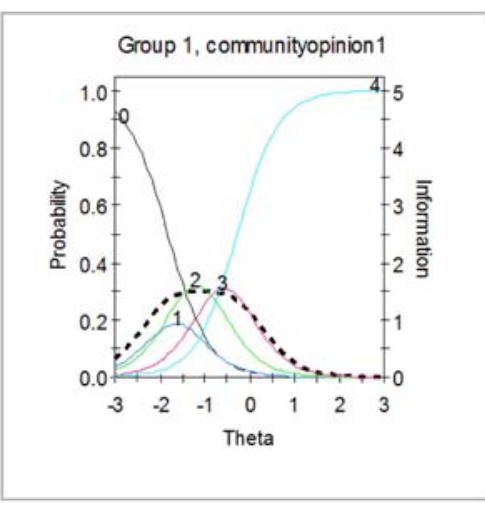

Community speaks well about doctor

\section{0 - Strongly Disagree}

1- Disagree

2- Neither Agree Nor

Disagree

3-Agree

4 - Strongly Agree Item Information

\section{Function}

\section{There is a big crowd in the clinic}

Figure 2 This figure shows the Item Characteristic Curves and Item Information Functions of items in the trust in physician scale. 


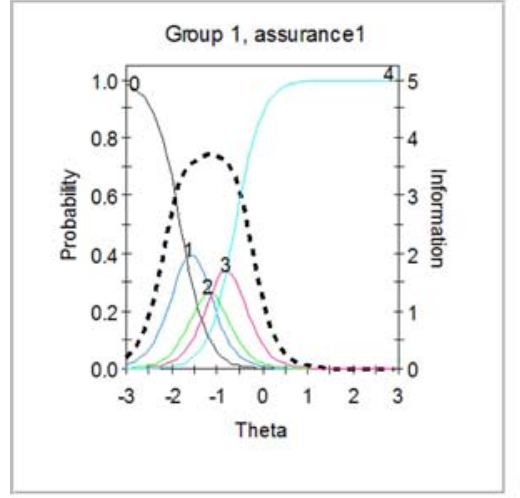

Assurance of good treatment

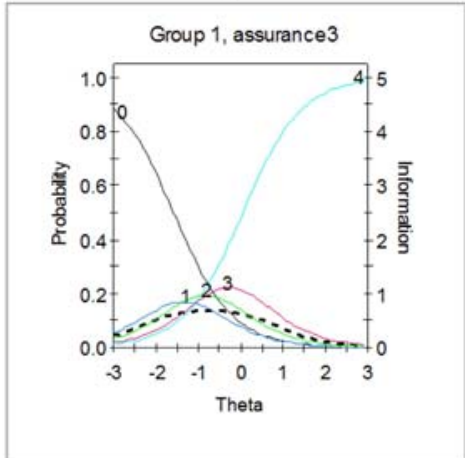

Assurance of treatment any time of day

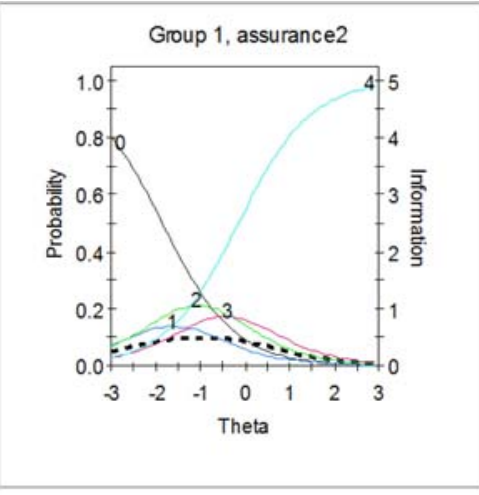

Good treatment irrespective of

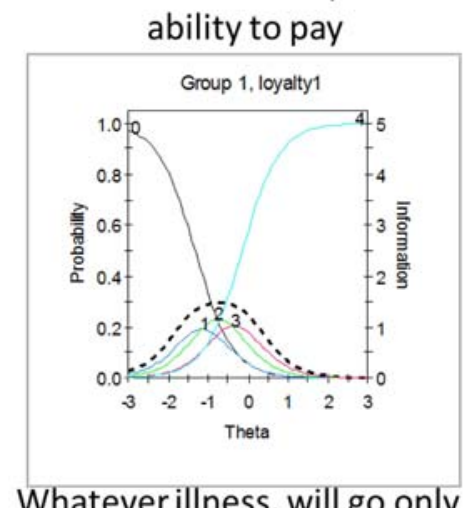

to this doctor

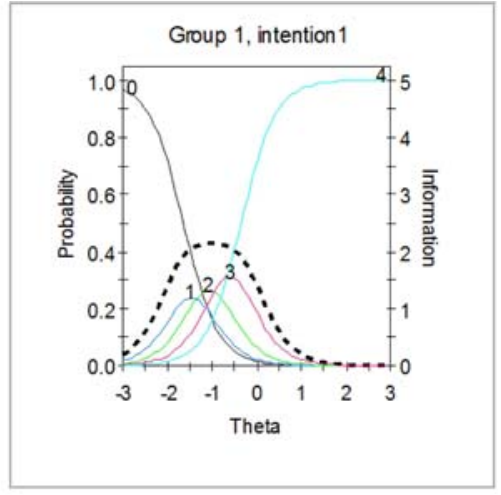

Main intention is relief of illness

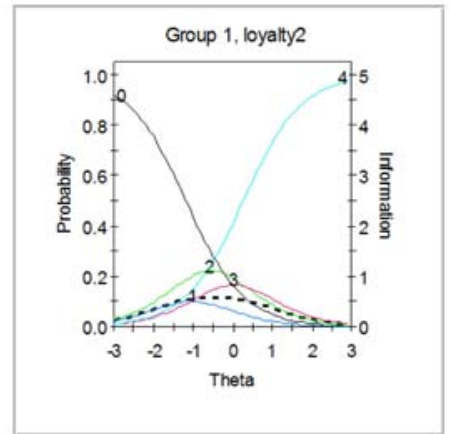

Will take other drugs only with permission

Figure 3 This figure shows the Item Characteristic Curves and Item Information Functions of items in the trust in physician scale.

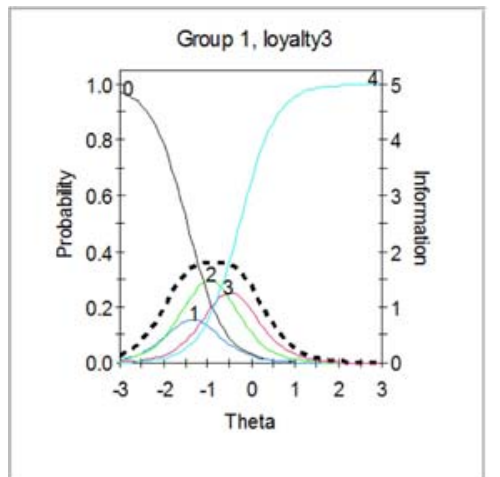

Will bring family members to this doctor

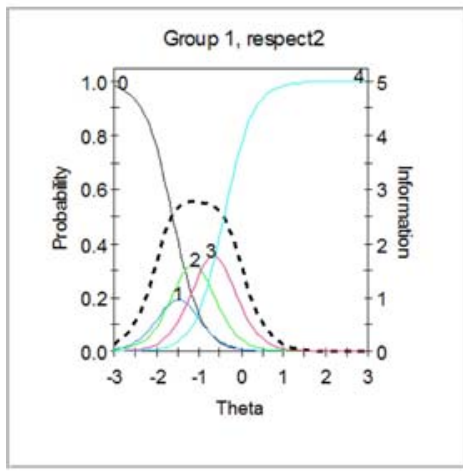

Doctor is a learned person

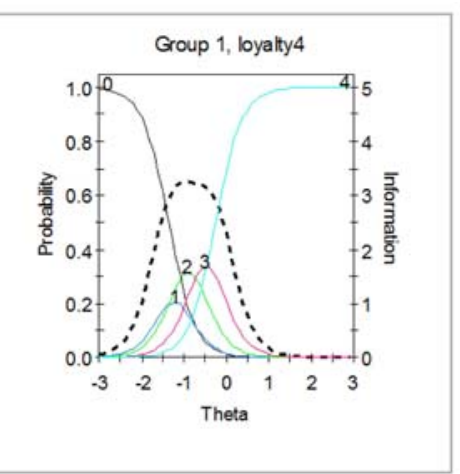

\section{Will recommend this} doctor to others

0 - Strongly Disagree

1- Disagree

2 - Neither Agree Nor

Disagree

3-Agree

4-Strongly Agree

........... Item Information

Function

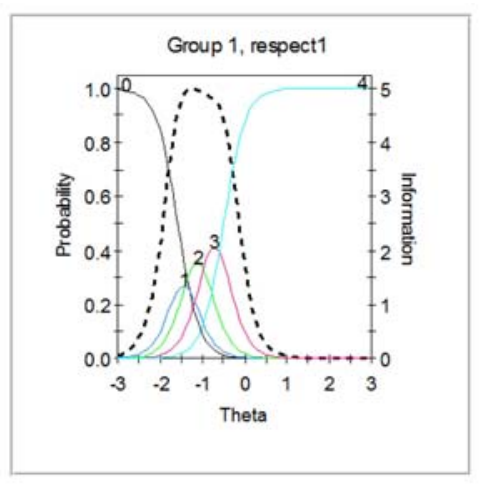

\section{Respect}

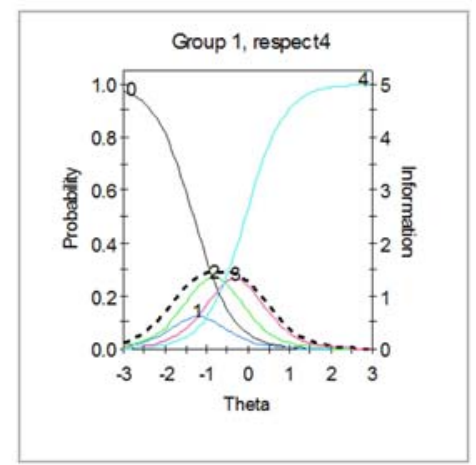

Admiration

Figure 4 This figure shows the Item Characteristic Curves and Item Information Functions of items in the trust in physician scale. 
measuring assurance of treatment. But the $\mathrm{LD} \mathrm{X}^{2}$ was not very high and hence no items were deleted from the model at this stage. The LD $\mathrm{X}^{2}$ matrix is shown in table 4 .

The AIC, BIC and $-2 \log$ likelihood ratios of the 1PL and 2PL models are shown in table 5. The Likelihood Ratio test value was 293.8 and for $21^{\circ}$ of freedom the $\mathrm{p}$ value was $<0.001$.

This indicated that the 2PL model was appropriate for the data. Table 6 shows the item parameters of all the 22 items.

It is clearly seen that most of the questions have a very high level of discrimination (a>1.70). ${ }^{42}$ The polytomous responses ranging from 'strongly disagree' to 'strongly agree' seem to perform optimally at increasing levels of the trust, ranging from -2.0 (low levels of trust) to +0.2 (moderate level of trust), without much overlap. Item level statistics of significance shows that 'appropriate medicines', 'relieves illness quickly', 'one visit is enough', 'confidence', 'will bring family members to the doctor', 'will recommend the doctor to others', 'respect' and 'admiration', are statistically significant items ( $p>0.05)$.

Item characteristic curves and item information curves for all the 22 items were examined. The item characteristic curves along with item information functions are shown in figures $1-4$. Of the 22 items, three had a high level of overlap between the Likert responses and poor item information; these were, 'prescribes expensive medicines for serious illness', 'assured of treatment at any time of the day' and 'will take treatment from other doctors only with the permission of this doctor'. The overall test information function is shown in figure 5 .

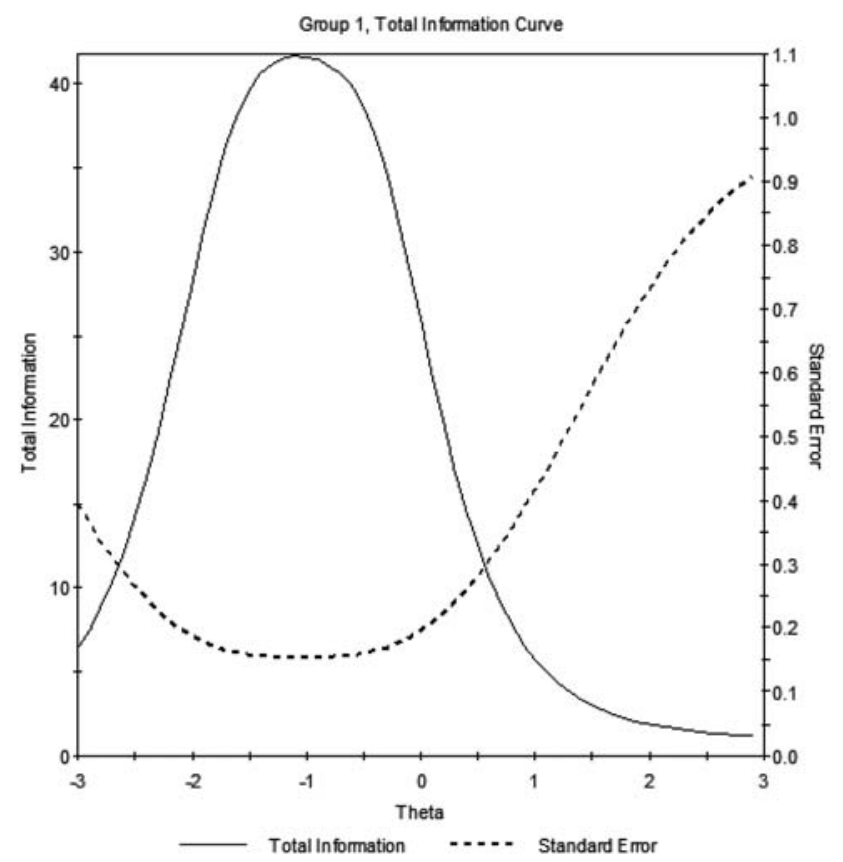

Figure 5 This figure shows the test information function of the 22 item scale. It is seen that the test performs optimally in the low to middle trust range but poorly in the high trust range.
The test information curve shows that maximum information is obtained at the trust $(\theta)$ levels of -1 to 0 . The performance of the scale is poor at the higher trust $(\theta)$ levels of +1 and +2 . It has a good range of performance between -2 and +1 . The test can be reliable between these trust levels, but reliability reduces below and above this range. The test functions optimally at low to moderate trust levels.

Based on the findings from the classical test theory approach, 'prescribed more expensive medicines for serious illnesses', 'presence of big crowd in the clinic', 'good treatment irrespective of ability to pay', 'good treatment at any time of the day' and 'taking permission of the doctor to take prescription of other doctors', were removed from the questionnaire as their item to total correlations were poor. Based on the item level parameters and item lever S-X ${ }^{2}$ statistic, 'one visit is enough for treatment', 'will bring family members to this doctor' and 'admiration', were removed as they were not statistically significant. The item characteristic curves and item information functions also reiterated the removal of the previously deleted items in the scale. The original list of items and the final list are compared in table 7.

\section{DISCUSSION}

This study has led to the development of a tool to measure trust in physicians in a resource poor setting in India. The tool has evolved organically from a qualitative exploration of the construct of trust in physicians. The qualitative exploration identified certain dimensions of trust that were unique to the regional cultural context in India, such as assurance of treatment irrespective of ability to pay, loyalty and respect. This study initially started with a pool of 31 questions to measure trust. After a series of classical and item response approaches, a final 12-item trust in physician scale was developed.

Before discussing the psychometric properties of the new scale, it is important to understand the nature of some of the items in this scale. The scale is unique for the developing country context because it has items in a language uniquely articulated by the community in the same setting during a previous qualitative study. For example, the item "there are no side effects for the medicines prescribed by the doctor" is representative of a "perceived competence" dimension of trust. In these settings, prescribing a medicine without (with minimal) side effects was perceived as a mark of competence. Similarly, the item "there is a big crowd in the clinic of this doctor" is representative of the "perceived competence" dimension because the crowd was perceived as an indicator of competence. The greater the crowd, the more competent the physician. The items representing the dimension of "treatment assurance at any time of the day, irrespective of the ability to pay" was also unique to this setting, and was articulated as a mark of trust. Also, some of the statements have been worded strongly, for example, "Whatever illness I have I will go only to this doctor first", because there was 
Table 7 Original list of items and items finally selected for the scale

Original list of items
The doctor does appropriate blood tests and other tests to diagnose

my disease

The doctor gives appropriate medications for my disease

The doctor prescribes appropriate number of medicines based on the nature of the illness

The doctor prescribed more expensive medicines for serious illnesses

The doctor's treatment relieves the illness quickly

The illness gets relieved with just one visit, there is no need for repeat visits

There are no side effects to the medicines prescribed by the doctor

Friends, relatives and neighbours speak well about the treatment provided by the doctor

Friends, relatives and neighbours recommend me to go to the doctor

I get the confidence that all my illness will get alright when I go to the doctor

There is a big crowd in the clinic of the doctor

If I go to the doctor, I will surely get good treatment for my illness

The doctor gives me good treatment irrespective of whether I have money to pay

The main intention of the doctor is to treat my illness and not anything else

Irrespective of what time of the day it is, whenever I go, I can get

good treatment from the doctor

Whatever illness I have, I will go only to this doctor

Even if I go to another doctor, I will take the treatment only if this

doctor approves it

I will bring my family members only to this doctor

I will recommend only this doctor to all those who ask me

I respect the doctor a lot

I think the doctor is a very learned person

I admire the doctor

\section{Items in the final scale}

The doctor does appropriate tests to diagnose my disease

The doctor gives appropriate medications for my disease

The doctor's treatment relieves the illness quickly

There are no side effects to the medicines prescribed by the doctor

Friends, relatives and neighbours recommend me to go to the doctor

I get the confidence that all my illness will get alright when I go to the doctor

If I go to the doctor, I will surely get good treatment for my illness

The main intention of the doctor is to treat my illness and not anything else

Whatever illness I have, I will go only to this doctor first

I will recommend this doctor to all those who ask me

I respect the doctor a lot

I think the doctor is a very learned person a heavy emphasis on the emotional dimension of these items during the qualitative exploration. However, during the psychometric assessment some of these items were excluded from the scale. This probably points towards the need for modifying these statements for future assessments and scale development exercises.

Classical test theory revealed that, except for five items, all the others had good correlation with the total score. Cronbach's $\alpha$ was 0.928 and deletion of any of the items did not alter it much, thus indicating strong internal consistency and stability. Item response analysis showed that all the items had good discrimination and gradient of the difficulty parameters, eight items were statistically significant and three items had poor item information functions.

As described previously in the methodology section, the classical test theory and item response theory approaches for psychometric scale development have their unique advantages and pitfalls. In this scale development process the classical test theory has provided a good estimate of the internal consistency and contribution of each question to the total score. The item response analysis has provided detailed description of the properties of each item, and estimates of item parameters and ability (trust) that are independent of the scale. Further, the sequential use of classical test and item response theory have utilised the advantages of both these methods and removed the relative disadvantages.

In tool development, there are certain important steps that have been described. The first step is generation of the items that will be included in the tool. It has been suggested that the items should be generated based on qualitative research among the target population. ${ }^{43}$ Many psychometric tools that attempt to measure trust have used item pools that have been generated based on literature review and pre-existing theoretical models. This is one of the few studies where a thorough 
qualitative exploration of trust was performed in the population of interest, dimensions of trust identified and a theoretical model proposed by grounded theory approach, and then items developed. ${ }^{22}$ The developed items were subject to thorough scrutiny by a panel of experts and the tool finalised. These steps take care of the face and content validity of the tool.

A previous exploration of the Trust in Physician Scale of Anderson and Dedrick revealed weak psychometric properties of the scale. ${ }^{43}$ This made it clear that existing scales could not be used to validate the new scale concurrently. A decision was made to assess the construct validity of the scale using the following methods: assessment of dimensionality using CFA and item information provided by each item about trust using item response analysis. The tool developed in this study is unidimensional, which is most likely to be trust, as the items were developed from qualitative exploration from the same population. Also, the individual items did perform well in terms of gradient of trust in the Likert scale as well as discrimination between low and high-trust individuals.

There are distinct differences between the new trust in physicians scale described here for the developing country context and previous scales of trust. Anderson and Dedrick's trust in physician scale had three dimensions, namely, fidelity, competence and confidentiality. ${ }^{1}$ Confidentiality did not feature as a dimension in the current scale. It was included in the original 31 items, but its contribution to the construct of trust was found to be negligible. The Medical Professions Trust Scale by Hall et $a l^{12}$ had an addition dimension of honesty, which was also seen in Hall's Trust in Primary Care Physician Scale and Zheng et $a l \mathbf{s}^{13}$ Health Insurance Organisation Trust Scale. The current scale does not feature this dimension of honesty. It is likely that honesty is featured inside the dimensions of respect, loyalty and assurance of treatment. A more thorough assessment of an honesty subscale would be useful to understand how this dimension is articulated in the trust discourse in this context. Straten et $a l \mathrm{~s}^{14}$ Whole Health System Trust Scale had the dimension of quality of care and effectiveness of communication. The main reason that these items did not feature in the current scale is because developing countries such as India are still struggling to achieve universal coverage. While issues of financial instability when accessing care, and uncertainty of access, are still issues, quality and communication are usually not considered important. This highlights the importance of contextually appropriate scales to measure trust in different settings.

The strengths of this study are that it is probably one of very few studies on tool development in public health where classical as well as item response approaches have been used. It has utilised the strengths of both the traditions to arrive at a parsimonious tool of 12 items to measure trust in doctors in the culturally unique Indian setting. The tool also seems to perform well over a broad range of low to moderate trust levels. This scale may not perform especially well in situations where there are very high levels/absence of trust. The main limitation of the study is that it has not addressed the issue of criterion validity or predictive validity. Future studies with the shortened 12 item scale that represents the identified key dimensions of trust in doctors in the Indian setting should try and validate the scale against definite criteria.

Acknowledgements The authors acknowledge Dr Mala Ramanathan, Professor of Public Health, Achuta Menon Centre for Health Sciences Studies, Sree Chitra Tirunal Institute of Medical Sciences and Technology, Trivandrum, India, for reviewing an earlier version of this paper. The authors also acknowledge anonymous peer reviewers whose comments for a previous submission of this paper significantly contributed to improvement of quality of the analysis and reporting.

Contributors VG conceptualised the study, designed the study instruments, collected data, analysed the data, interpreted data, drafted the manuscript and approved the final draft. EW Contributed to conceptualisation of the study, edited the manuscript draft and approved the final draft. SKC conceptualised the study, helped in design of study instrument, edited the manuscript and approved the final draft.

Funding The first author, VG, was supported by the INSPIRE Fellowship of the Department of Science and Technology, Government of India.

Competing interests None declared.

Patient consent Obtained.

Ethics approval Institutional Review Board and ethics committee of the School of Public Health, SRM University.

Provenance and peer review Not commissioned; externally peer reviewed.

Data sharing statement The data set is available with the corresponding author who will provide it on request.

Open Access This is an Open Access article distributed in accordance with the Creative Commons Attribution Non Commercial (CC BY-NC 4.0) license, which permits others to distribute, remix, adapt, build upon this work noncommercially, and license their derivative works on different terms, provided the original work is properly cited and the use is non-commercial. See: http:// creativecommons.org/licenses/by-nc/4.0/

\section{REFERENCES}

1. Anderson LA, Dedrick RF. Development of the trust in physician scale: a measure to assess interpersonal trust in patient-physician relationships. Psychol Rep 1990;67(3 Pt 2):1091-100.

2. Caterinicchio RP. Testing plausible path models of interpersonal trust in patient-physician treatment relationships. Soc Sci Med Med Psychol Med Sociol 1979;13:81-99.

3. David AS. Communicating in times of uncertainty: the need for trust. $J$ Health Commun 2003;8(S1):13-14.

4. Zaner RM. The phenomenon of trust and the patient-physician relationship. Ethics Trust Prof Philos Cultur Aspects 1991;45-67.

5. Thom DH, Hall MA, Pawlson LG. Measuring patients trust in physicians when assessing quality of care. Health Aff 2004;23:124-32.

6. Safran DG, Taira DA, Rogers $\mathrm{WH}$, et al. Linking primary care performance to outcomes of care. J Fam Pract 1998;47:213-20.

7. Piette JD, Heisler M, Krein S, et al. The role of patient-physician trust in moderating medication nonadherence due to cost pressures. Arch Intern Med 2005;165:1749.

8. Trachtenberg F, Dugan E, Hall MA. How patients trust relates to their involvement in medical care. J Fam Pract 2005;54:344-52.

9. Thom DH, Ribisl KM, Stewart AL, et al. Further validation and reliability testing of the Trust in Physician Scale. Med Care 1999;37:510.

10. Lee YY, Lin JL. The effects of trust in physician on self-efficacy, adherence and diabetes outcomes. Soc Sci Med 2009;68:1060-8.

11. Mohseni M, Lindstrom M. Social capital, trust in the health-care system and self-rated health: the role of access to health care in a population-based study. Soc Sci Med 2007;64:1373-83. 
12. Hall MA, Zheng B, Dugan E, et al. Measuring patients' trust in their primary care providers. Med Care Res Rev 2002;59:293-318.

13. Zheng B, Hall MA, Dugan E, et al. Development of a scale to measure patients' trust in health insurers. Health Serv Res 2002;37:187-202.

14. Straten GFM, Friele RD, Groenewegen PP. Public trust in Dutch health care. Soc Sci Med 2002;55:227-34.

15. Goudge J, Gilson L. How can trust be investigated? Drawing lessons from past experience. Soc Sci Med 2005;61:1439-51.

16. Egede LE, Ellis C. Development and testing of the multidimensional trust in health care systems scale. $J$ Gen Intern Med 2008;23:808-15.

17. Dugan E, Trachtenberg F, Hall M. Development of abbreviated measures to assess patient trust in a physician, a health insurer, and the medical profession. BMC Health Serv Res 2005;5:64.

18. Goold SD, Fessler D, Moyer CA. A measure of trust in insurers. Health Serv Res 2006;41:58-78.

19. Rose A, Peters N, Shea JA, et al. Development and testing of the health care system distrust scale. J Gen Intern Med 2004;19:57-63.

20. Leisen B, Hyman MR. An improved scale for assessing patients' trust in their physician. Health Mark Q 2001;19:23-42.

21. Makinen $M$, Waters $H$, Rauch $M$, et al. Inequalities in health care use and expenditures: empirical data from eight developing countries and countries in transition. Bull World Health Organ 2000;78:55-65.

22. Gopichandran V, Chetlapalli SK. Dimensions and determinants of trust in health care in resource poor settings-a qualitative exploration. PLOS ONE 2013;8:e69170.

23. Baidya M, Gopichandran V, Kosalram K. Patient physician trust among adults of rural Tamil Nadu: a community based survey. $J$ Postgrad Med 2014;60:21-6.

24. Ramani KV, Mavalankar D. Health system in India: opportunities and challenges for improvements. $J$ Health Organ Manag 2006;20:560-72.

25. Peters DH, Muraleedharan VR. Regulating India's health services: to what end? What future? Soc Sci Med 2008;66:2133-44.

26. OECD. OECD Health Data 2012. 2012.
27. Roy K, Howard DH. Equity in out-of-pocket payments for hospital care: evidence from India. Health Policy 2007;80:297-307.

28. Balabanova D, Mills A, Conteh L, et al. Good Health at Low Cost 25 years on: lessons for the future of health systems strengthening. Lancet 2013;381:2118-33.

29. Kotrlik JWKJ, Higgins CCHC. Organizational research: determining appropriate sample size in survey research appropriate sample size in survey research. Info Technol Learn Perform J 2001;19:43.

30. Hambleton RK, Jones RW. Comparison of classical test theory and item response theory and their applications to test development. Educ Meas 1993;12:38-47.

31. SPSS Inc. SPSS Statistics for Windows Version 17.0, 2008.

32. IBM SPSS Amos Version 20, 2011.

33. Paek I, Han KT. IRTPRO 2.1 for windows (item response theory for patient-reported outcomes). Appl Psychol Meas 2013;37:242-52.

34. Hooper D, Coughlan J, Mullen M. Structural equation modelling: guidelines for determining model fit. Electronic $J$ Business Res Methods 2008;6:53-60.

35. Chen WH, Thissen D. Local dependence indexes for item pairs using item response theory. J Educ Behav Stat 1997;22:265-89.

36. Samejima F. Graded response model. Handbook of modern item response theory. Springer, 1997:85-100.

37. Kang T, Cohen AS, Sung HJ. Model selection indices for polytomous items. Appl Psychol Meas 2009;33:499-518.

38. Navaneetham K, Dharmalingam A. Demography and development: preliminary interpretations of the 2011 census. Econ Pol Weekly 2011;46:13.

39. Dyson T. The preliminary demography of the 2001 census of India Popul Dev Rev 2001;27:341-56.

40. Chowdhury S. Employment in India: what does the latest data show? Econ Pol Weekly 2011;46:23-6.

41. Nunnally JC, Bernstein IH. Psychometric Theory. 3rd edn. New York: McGraw-Hill, 1994.

42. DeMars C. Item response theory. Oxford University Press, 2010.

43. Streiner DL, Norman GR. Health measurement scales: a practical guide to their development and use. Oxford University Press, 2008. 